\title{
Molecular epidemiology and socio- demographic risk factors of sexually transmitted infections among women in Lebanon
}

Jessica Hanna ${ }^{1 \dagger}$, Ruba Yassine ${ }^{1 \dagger}$, Rana El-Bikai ${ }^{1}$, Martin D. Curran², Mathilde Azar ${ }^{1}$, Joumana Yeretzian ${ }^{1}$, Rana Skaf ${ }^{3,4}$, Claude Afif ${ }^{3}$, Toufic Saber ${ }^{3}$, Saadeddine Itani ${ }^{5}$, Manal Hubeish ${ }^{5}$, Tamima El Jisr ${ }^{5}$, Fadia Hamzeh ${ }^{6}$ and Mira El Chaar ${ }^{1 *}$

\begin{abstract}
Background: Sexually transmitted infections (STIS) cause a major public health problem that affect both men and women in developing and developed countries. The aim of the study was to estimate the prevalence of 11 STIs among women who voluntarily participated in the study, while seeking gynecological checkup. The existence of an association between the presence of pathogens and symptoms and various sociodemographic risk factors was assessed.

Methods: A total of 505 vaginal and cervical specimens were collected from women above 18 years of age, with or without symptoms related to gynecological infections. Nucleic acid was extracted and samples were tested by realtime PCR for the following pathogens: Chlamydia trachomatis, Neisseria gonorrhoeae, Mycoplasma genitalium, Ureaplasma urealyticum, Urealplasma parvum, Trichomonas vaginalis, Mycoplasma hominis, Mycoplasma girerdii, Gardnerella vaginalis, Candida albicans and Human Papillomavirus (HPV). Positive HPV samples underwent genotyping using a microarray system.

Results: Of the 505 samples, 312 (62\%) were screened positive for at least one pathogen. Of these, 36\% were positive for Gardnerella vaginalis, 35\% for Ureaplasma parvum, 8\% for Candida albicans, 6.7\% for HPV, 4.6\% for Ureaplasma urealyticum, 3.6\% for Mycoplasma hominis, 2\% for Trichomonas vaginalis, 0.8\% for Chlamydia trachomatis, $0.4 \%$ for Mycoplasma girerdii, $0.2 \%$ for Mycoplasma genitalium and $0.2 \%$ for Neisseria gonorrhoeae. Lack of symptoms was reported in 187 women (37\%), among whom 61\% were infected. Thirty-four samples were HPV positive, with 17 high risk HPV genotypes (HR-HPV); the highest rates being recorded for types 16 (38\%), 18 (21\%) and 51 (18\%). Out of the 34 HPV positives, 29 participants had HR-HPV. Association with various risk factors were reported.

(Continued on next page)
\end{abstract}

\footnotetext{
* Correspondence: mira.elchaar@balamand.edu.lb

${ }^{+}$Jessica Hanna and Ruba Yassine contributed equally to this work.

${ }^{1}$ Faculty of Health Sciences, University of Balamand, P.O.Box 166378 Ashrafieh, Beirut 1100-2807, Lebanon

Full list of author information is available at the end of the article
}

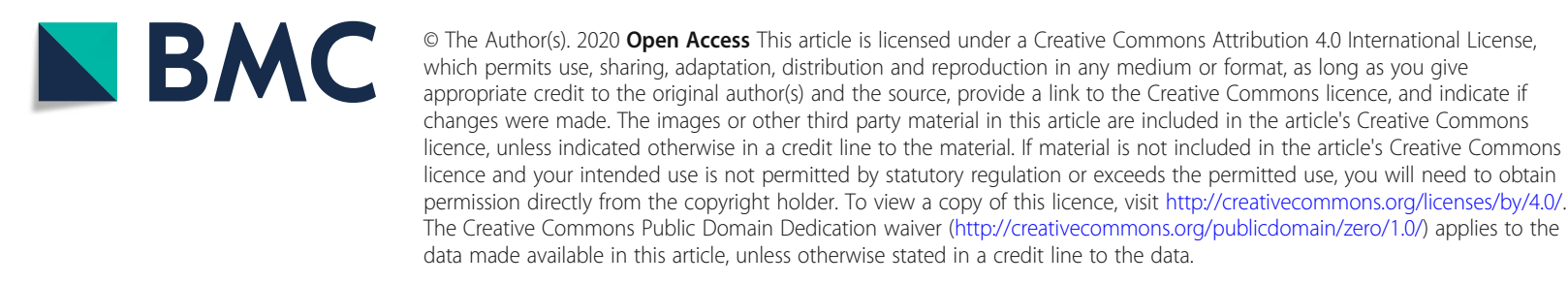


(Continued from previous page)

Conclusions: This is the first study that presents data about the presence of STIs among women in Lebanon and the MENA region by simultaneous detection of 11 pathogens. In the absence of systematic STI surveillance in Lebanon, concurrent screening for HPV and PAP smear is warranted.

Keywords: STIs, HPV genotyping, Surveillance, Molecular detection, Clinical symptoms, Risk factors

\section{Background}

Sexually transmitted infections (STIs) cause a major public health problem; they affect both men and women in developing and developed countries. There are more than 30 types of STIs caused by different pathogens including bacteria, viruses and parasites that may differ in their clinical manifestations [1]. STIs are frequently asymptomatic and can lead to various complications such as pelvic inflammatory disease, infertility, ectopic pregnancy, cervical cancer and congenital infections in infants born to infected mothers [2-6]. Estimating the prevalence of STIs is essential to prevent, control and properly treat individuals carrying the infections.

The development of new technologies that include nucleic acid amplification platforms, such as multiplex PCR assays, have improved the diagnosis and reporting of various infections $[7,8]$. The burden of STIs has long been underestimated by the public health sector overlooking the "hidden epidemics" of such diseases. However, recently the alarm has been triggered to battle these infections where CDC, WHO and other organizations have conducted global plans which will contribute to a radical decline in new STIs and in deaths related to such infections [9].

There are limited STI surveillance reports published in the MENA region. In Lebanon, routine screening for all potential STIs is cost-prohibitive, limiting the knowledge about transient carriers and transfer of pathogens. Premarital sexual intercourse is becoming more common in Lebanon $[10,11]$. This fact is coupled with sexual behavior shifts such as an increase in multiple partners and homosexuality practices, both of which are linked to increased risks of STIs [10-12]. Generally, sexual and reproductive health quality services, such as screening, diagnosis and preventive checkups, are not easily accessible and are cost prohibitive. Women may usually seek medical attention for cycle variations, abnormal vaginal secretions or cervical screening.

The aim of the study was to estimate the prevalence of eleven STIs among women seeking gynecological checkups, evaluate the occurrence of concomitant STIs, and assess the existence of an association between the presence of pathogens and symptoms and various sociodemographic risk factors. Determining the presence of STIs is essential to improve the reporting system in the country and to develop appropriate health care strategies that focus on preventive and protective measures.

\section{Methods}

\section{Study design}

A cross-sectional study was conducted in Beirut, Lebanon between November 2016 and December 2017. An estimated number of 377 subjects was determined using the Raosoft online sample calculator with alpha 0.05 and a confidence interval of 95\% [13]. Participants were collected using a convenience sample of 505 women seeking gynecological checkups in private clinics located in three large tertiary hospital centers and two dispensaries in Beirut, Lebanon. These sites receive a high number of patients from various sociodemographic and socioeconomic status.

Women aged 18 years and above, presenting with or without symptoms of possible reproductive tract infections were included. Whereas, women who underwent hysterectomy or claimed not to have any kind of previous sexual intercourse were excluded. Since specimen collection may include a mild invasive procedure, pregnant women were excluded from this study for safety reasons. On the other hand, all nonpregnant women who were approached, voluntarily participated in the study, knowing that the screening was free of charge.

\section{Ethical consideration}

This study was approved by the institutional review board of Saint George Hospital and Makassed General Hospital. A written informed consent was obtained from all eligible women before entering the study. Women were informed about the study, their participation was voluntary and they had the right to withdraw at any moment. The risks and benefits were clearly explained. Results were communicated to the gynecologists who reported them to patients.

\section{Data collection}

The healthcare practitioners, including physicians, midwives or nurses, were responsible for collecting the samples and filling the questionnaires with the patients. Data collection included information about the sociodemographic profile of patients, their lifestyle, habits as well as their medical and sexual history. The 
questionnaires were completed having less than $10 \%$ missing data on some questions except for the item on job occupancy which had $15 \%$ missing data. Clinical symptoms such as painful urination, abdominal pain, discharge, itching, painful intercourse, bleeding in urine and bleeding post sexual intercourse were recorded. Clinical symptoms were not filled in $12 \%(N=61)$ of the questionnaires. For women who had a positive HPV results in our selected sample, follow-up with their healthcare providers showed that only 17 of them underwent a Papanicolaou (PAP) smear test simultaneously. Data were reported in our results to determine if there are discrepancies between presence of the HPV infection and PAP smear pathological results.

\section{Sample collection and DNA extraction}

Two genital flocking swabs (endocervical and vaginal) were collected from each woman and placed in a single tube containing universal transport media (Copan Diagnostics Inc., Murietta, USA) and stored prior to testing at $-80^{\circ} \mathrm{C}$.

DNA from $200 \mu \mathrm{l}$ of each sample was extracted from the collected tubes using a QIAamp DNA extraction kit (Qiagen, Hilden, Germany) according to the manufacturer's protocol. An artificial single stranded molecule was used as an internal control [14] for all samples prior to extraction. DNA was concentrated in $60 \mu \mathrm{l}$ of elution buffer.

\section{Multiplex PCR for the detection of ten pathogens}

Four multiplex PCR assays that include two quadriplex and two duplex assays were used to test for the presence of 10 pathogens: Chlamydia trachomatis, Neisseria gonorrhoeae, Mycoplasma genitalium, Ureaplasma urealyticum, Ureaplasma parvum, Trichomonas vaginalis, Mycoplasma hominis, Mycoplasma girerdii, Gardnerella vaginalis and Candida albicans.

Primers-probes sets were purchased from Metabion (Planegg/steinkirchen, Germany) and Thermofisher (Massachusetts, USA) (Table S1). Positive controls were kindly donated by Addenbrooke's hospital clinical microbiology laboratory, Cambridge, UK. The $12.5 \mu \mathrm{l}$ duplex or quadriplex PCR reactions included $12.5 \mu \mathrm{l}$ of Platinum Quantitative PCR SuperMix-UDG (Invitrogen Carlsbad,CA), $3 \mathrm{mM} \mathrm{MgSO} 4,6.25 \mathrm{pmol}$ of forward and reverse primers, $2.5 \mathrm{pmol}$ of fluorogenic probes, and $5 \mu \mathrm{l}$ of purified nucleic acid. The reaction was initiated by two heating steps at $50{ }^{\circ} \mathrm{C}$ for $2 \mathrm{~min}$ and $95^{\circ} \mathrm{C}$ for $2 \mathrm{~min}$ followed by 45 amplification cycles with the following conditions: $95^{\circ} \mathrm{C}$ for $15 \mathrm{~s}$ and $60{ }^{\circ} \mathrm{C}$ for $60 \mathrm{~s}$. The appropriate fluorescence reading was performed at $60^{\circ} \mathrm{C}$.

\section{Detection of HPV genotypes}

A real time PCR monoplex reaction that target the L1 open reading frame of HPV was performed using the GP5+/6+ consensus primers pairs (GP5+ primer: 5' TTTGTTACTGTGGTAGATACTAC-3' and GP6+ primer 5'-GAAAAATAAACTGTAAATCATATTC-3') [15]. A universal taqman MGB probe was designed and used for this study: 5' - FAM-CATGNNGARGAATA TG-MGB-3'. The PCR reaction was done using Platinum Quantitative PCR SuperMix-UDG as previously described.

Positive HPV samples were screened for HPV genotypes using EUROArray HPV kit (Euroimmun, New Jersey, USA). The kit includes amplification and hybridization steps that identify 30 different HR and LR HPV types. The kit is based on the amplification of E6 and E7 viral oncogenes fragments and their detection via hybridization with immobilized DNA probes $[16,17]$.

The assay was performed according to the manufacturer's instructions. The first reaction was a Pre-PCR step that included $10 \mu \mathrm{l}$ of PCR Mix A and $10 \mu \mathrm{l}$ of PCR Mix B and $5 \mu$ l of the extracted sample DNA. The PCR reactions were performed on the CFX96 real-time PCR machine (Bio-Rad, California, USA). Each PCR product was mixed with $65 \mu \mathrm{l}$ of Hybridization buffer and incubated at $45^{\circ} \mathrm{C}$ for $60 \mathrm{~min}$ on a microarray slide. Slides were washed with buffer, dried and read on the Microarray Scanner and EUROArray Scan software that detects signal strength in terms of immunofluorescence units.

\section{Statistical analysis}

Data analysis was performed using SPSS (version 20.0). Descriptive analysis including frequencies, percentages and averages were used when appropriate to describe the population under study. Prevalence was calculated to indicate the number of subjects carrying STIs among the recruited sample. A chi-square test was used to assess the association between exposures and outcomes expressed as categorical variables. The threshold for significance was set at alpha 0.05. Univariate and multivariate logistic regression were used to calculate odds of infection relative to variables that showed significance at the bivariate level. Odds ratios were considered significant if the 95\% confidence interval excluded 1 .

\section{Results}

\section{Prevalence of pathogens}

Eleven pathogens were identified as causing STI among $62 \%(N=312)$ of the participants. Bacteria were identified in $58 \%(N=295)$ of the patients; $8.1 \%$ were positive for C.albicans $(N=41), 6.7 \%$ for $\mathrm{HPV}(N=34)$ and $2 \%$ for T.vaginalis $(N=10)$. The pathogens causing bacterial infections were $36 \%$ for G.vaginalis $(N=184)$, $35 \%$ for 
U.parvum $(N=175), 4.6 \%$ for U.urealyticum $(N=23)$, $3.6 \%$ for M.hominis $(N=19), 0.8 \%$ for C.trachomatis $(N=4), 0.4 \%$ for M.girerdii $(N=2), 0.2 \%$ for M.genitalium $(N=1)$, and $0.2 \%$ for N.gonorrhoeae $(N=1)$ (Table 1).

Urogenital pathogens were isolated from women as either single infection or coinfections. The presence of a single pathogen was recovered from 140 women (28\%). The remaining urogenital pathogens were diversely recovered from women as two $(34 \%, N=129)$, three $(6.5 \%, N=33)$, four $(1.8 \%, N=9)$ or six coinfections $(0.2 \%, N=1)$ (Table 1$)$.

\section{Association between pathogens and symptoms In symptomatic patients}

Among the 505 women, 50\% $(N=257)$ reported having genital clinical symptoms, of whom $64 \%$ $(N=165)$ were positive for the tested pathogens. A high rate of U.parvum and G.vaginalis coinfection was observed $(N=103)$, among which only $49 \%$ were seen as symptomatic. No significant association was however observed between the presence of studied pathogens (when detected as single or multiple infections) and the presence of any symptoms $(p=0.330)$.

\section{In asymptomatic patients}

Lack of symptoms was reported in $37 \%(N=187)$ of the women, of whom $61 \%(N=114)$ were carrying the pathogens (Fig. 1). The most commonly isolated pathogens from these 114 patients were $U$. parvum, G.vaginalis, $C$. albicans and $U$. urealyticum with 54, 37, 33 and 29\%, respectively.

\section{Rates of HPV genotypes}

The HPV positive samples $(N=34)$ had varied HPV genotype combinations of HR-HPV and LR-HPV (Table S2) with different prevalence rates and percentages. Figure 2 reveals the presence of 17 HR-HPV genotypes detected in the samples; the highest rates being recorded for types $16(38 \%, N=13)$ and $18(21 \%, N=7)$. A lower prevalence of LR-HPV was observed where 11 LR-HPV genotypes were identified, with the highest number of patients being recorded for types $54(17.6 \%, N=6)$ and $42(11.7 \%, N=4)$. HPV genotypes were grouped on the basis of their presence as single, double, triple or more genotypes (Table S2); the highest percentage was observed as a single HPV genotype reaching $44 \%(N=15)$. HPV genotype 16 was found as a single genotype in five women (33\%). As the number of coinfecting HPV genotypes increases, the percentage of women positive for more than one genotype decreases from $24 \%(N=8)$ for

Table 1 Total number of STIs detected in 505 women

A

\begin{tabular}{|c|c|c|c|c|c|c|c|c|c|c|c|}
\hline Pathogens & $\mathrm{CT}$ & NG & MG & MGI & MH & UU & UP & GV & CA & TV & HPV \\
\hline CT & 4 & 1 & 0 & 1 & 1 & 0 & 3 & 3 & 1 & 1 & 0 \\
\hline NG & & 1 & 0 & 0 & 0 & 0 & 0 & 1 & 0 & 0 & 0 \\
\hline MG & & & 1 & 0 & 0 & 0 & 1 & 0 & 0 & 0 & 0 \\
\hline MGI & & & & 2 & 1 & 0 & 1 & 1 & 0 & 2 & 0 \\
\hline MH & & & & & 19 & 2 & 14 & 16 & 3 & 3 & 5 \\
\hline UU & & & & & & 23 & 2 & 13 & 2 & 0 & 3 \\
\hline UP & & & & & & & 175 & 103 & 18 & 3 & 17 \\
\hline GV & & & & & & & & 184 & 22 & 4 & 16 \\
\hline$C A$ & & & & & & & & & 41 & 1 & 2 \\
\hline TV & & & & & & & & & & 10 & 1 \\
\hline HPV & & & & & & & & & & & 34 \\
\hline
\end{tabular}

B 


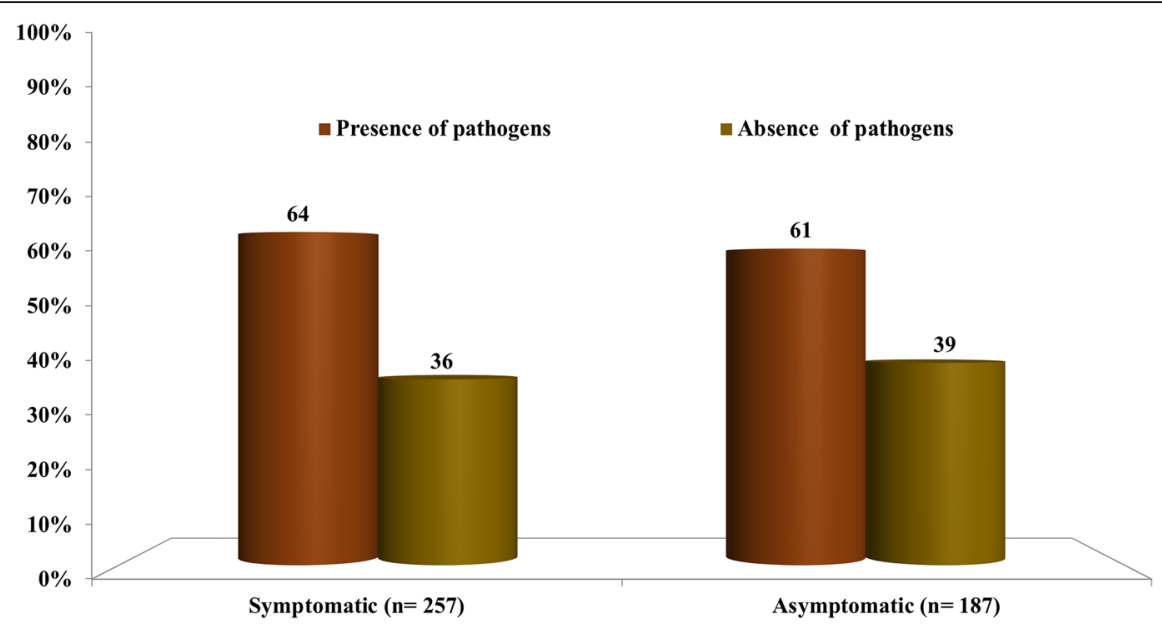

Fig. 1 Percentage of pathogens isolated from symptomatic and asymptomatic women

2 types, to $12 \%(N=4)$ for 3 types, reaching $3 \%(N=1)$ for 8 simultaneous genotypes (Table S2). The authors were not able to propose a pattern of HPV genotypes prevalence among positive samples that has reached a statistical significance (Table S2).

\section{Pap test and HPV}

Further investigations were conducted for the $17 \mathrm{HPV}$ positive patients who had PAP smear.

Their age ranged between 21 and 39 years old with the majority being 21 and 29 years $(N=12,71 \%)$. Five patients had normal cytological results in the presence of HR-HPV (Table S3). The remaining patients had cytological changes in the presence of HPV.

\section{HPV vaccination in HPV infected women}

From the 505 participants, 20 (4\%) had taken HPV vaccine. Of the vaccinated women, 7 (35\%) were positive for HPV. By observing the genotype combination present in the 7 women, two had one of the HR-HPV genotypes present in all HPV vaccines; one female was positive for HR-HPV type 16 and another for HR-HPV

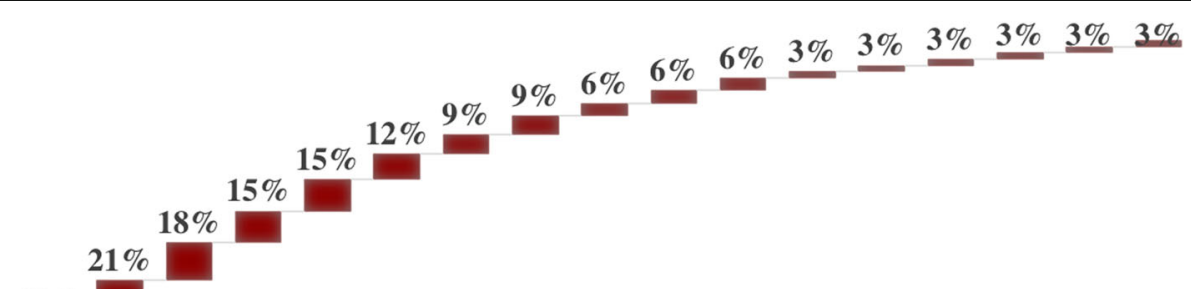

High risk HPV (17 genotypes)

$\begin{array}{lllllllllllllllll}16 & 18 & 51 & 26 & 39 & 73 & 45 & 53 & 33 & 35 & 59 & 31 & 52 & 56 & 58 & 66 & 82\end{array}$

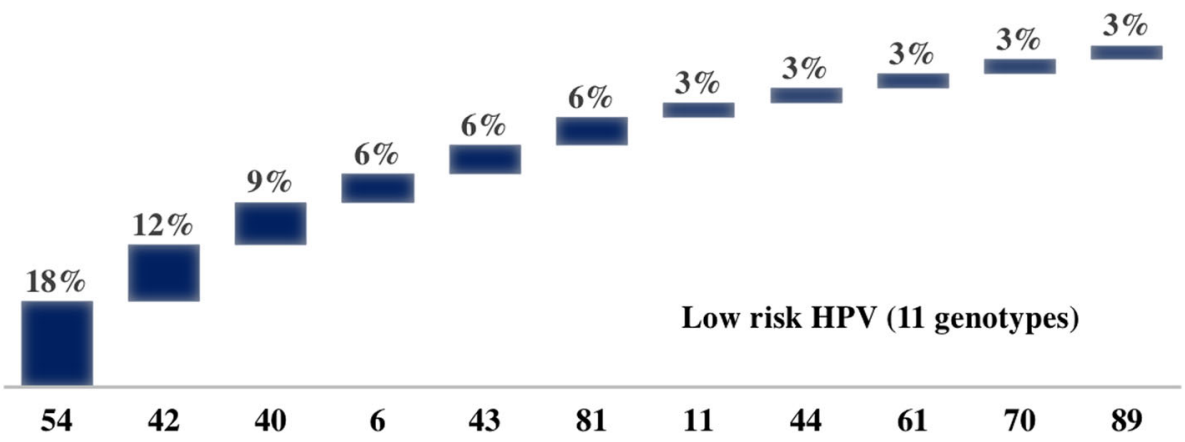

Fig. 2 Distribution of High Risk and Low Risk HPV isolated from 34 women 
type 18 along with other HPV genotypes. Three women were infected with LR-HPV genotypes.

\section{Demographic characteristics of the sample and their association with STI's}

A total of 505 women aged between 18 and 69 years, with a mean age of 38 years $(\mathrm{SD}=10.8)$, were enrolled in this study; a third of the women who participated were between the ages of 30 to 39 years old (32.8\%). The majority were Lebanese (63.6\%) and housewives (63.6\%) (Table 2). As for the marital status, a high number of women were married (86.2\%). Most of the women $(77.8 \%)$ reported having had only one sexual partner while $0.01 \%$ had more than three.

\section{Sociodemographic and behavioral risk factors and their association with STIs}

There was a statistically significant association between marital status $(p=0.000)$ and the presence of infection. Eighty-six percent $(86 \%)$ of single women had an infection compared to $61 \%$ of married women and $40 \%$ of divorced/widowed women. No association was observed between nationality and the presence of infection.

A significant association was observed between the presence of infection and age groups, with a higher proportion among younger women aged between 18 and 29 (73.9\%) compared to older women (50 to 69) (43.8\%) $(p=0.000)$.

We have seen that C.albicans was prominent in the age group 30-39 $(p=0.058)$. Coinfections were mostly observed in women aged between 18 and 29 years, while women aged 50 and above were either not colonized (56\%) by the studied pathogens or colonized by a single pathogen (25\%) (Fig. 3). However, no association was observed between the age group and coinfections.

Among the 34 women infected with HPV, 14 ranged between 21 and 29 years (median age of 30 years). Moreover, it was noticed that as age increases the presence of HPV decreases: 11 women ranged between 30 and 39 years, 5 women between 40 and 49 years and 4 women between 50 and 59 years.

Other findings revealed that a combination of $\geq 3 \mathrm{HPV}$ genotypes were most likely found in age groups 20-29 and 30-39 while older age groups, 40-49 and 50-59, had either one or two genotypes (Table S2).

Women who reported to smoke and drink alcohol were 32 and $16 \%$ respectively. The only significant association between behavioral risk factors and the presence of infection was the consumption of alcohol with $73 \%$ being infected among consumers compared to 59\% among non-consumers $(p=0.015)$.

Only 162 women (32\%) were using contraceptives, with intrauterine device being the most frequently used $(N=87,53.7 \%)$. The presence of infection was
Table 2 Demographic characteristics and behavioral risk factors of the 505 women in the sample

\begin{tabular}{|c|c|c|}
\hline & $\begin{array}{l}\text { Total } \\
\text { (\%) N }\end{array}$ & $\begin{array}{l}\text { Positive for STIs } \\
\text { (\%) N }\end{array}$ \\
\hline \multicolumn{3}{|l|}{ Nationality $(N=455)$} \\
\hline Lebanese & $63.3 \%(288)$ & $57.9 \%(167)$ \\
\hline Syrian & $24.2 \%(110)$ & $67.2 \%(74)$ \\
\hline Palestinian & $8.8 \%(40)$ & $60 \%(24)$ \\
\hline Other & $3.7 \%(17)$ & $82.3 \%(14)$ \\
\hline Missing & 50 & \\
\hline \multicolumn{3}{|l|}{ Age Range $(N=448)$} \\
\hline $18-29$ & $27.5 \%(123)$ & $73.9 \%(91)$ \\
\hline $30-39$ & $32.8 \%(147)$ & $59.1 \%(87)$ \\
\hline $40-49$ & $23.4 \%(105)$ & $62.8 \%(66)$ \\
\hline $50-69$ & $16.3 \%(73)$ & $43.8 \%(32)$ \\
\hline Missing & 57 & \\
\hline \multicolumn{3}{|c|}{ Employment $(N=431)$} \\
\hline None (housewife) & $63.6 \%(274)$ & $59.4 \%(163)$ \\
\hline Yes & $6.0 \%(26)$ & $66.9 \%(17)$ \\
\hline Missing & 74 & \\
\hline \multicolumn{3}{|c|}{ Marital Status $(N=486)$} \\
\hline Single & $7.6 \%(37)$ & $86.4 \%(32)$ \\
\hline Divorced/Widowed & $6.2 \%(30)$ & $40 \%(12)$ \\
\hline Currently Married & $86.2 \%(419)$ & $60.6 \%(254)$ \\
\hline Missing & 19 & \\
\hline \multicolumn{3}{|c|}{ Behavioral Risk Factors } \\
\hline \multicolumn{3}{|l|}{ Alcohol $(N=487)$} \\
\hline Yes & $16.2 \%(79)$ & $73.4 \%(58)$ \\
\hline No & $83.7 \%(408)$ & $58.8 \%(240)$ \\
\hline Missing & 18 & \\
\hline \multicolumn{3}{|l|}{ Smoking $(N=488)$} \\
\hline Yes & $32.1 \%(157)$ & $66.2 \%(104)$ \\
\hline No & $67.8 \%(331)$ & $58.9 \%(195)$ \\
\hline Missing & 17 & \\
\hline \multicolumn{3}{|c|}{ Contraceptive Use $(N=458)$} \\
\hline Yes & $36.5 \%(167)$ & $65.2 \%(109)$ \\
\hline No & $63.5 \%(291)$ & $58.4 \%(170)$ \\
\hline Missing & 47 & \\
\hline \multicolumn{3}{|c|}{ Contraceptive Type $(N=162)$} \\
\hline Intrauterine Device & $53.7 \%(87)$ & $71.2 \%(62)$ \\
\hline Pills & $27.2 \%(44)$ & $63 . \%(28)$ \\
\hline Male Condom & $17.9 \%(29)$ & $44.8 \%(13)$ \\
\hline Loop & $0.6 \%(1)$ & $100 \%(1)$ \\
\hline Female Condom & $0.6 \%(1)$ & $0 \%(0)$ \\
\hline Missing & 5 & \\
\hline
\end{tabular}




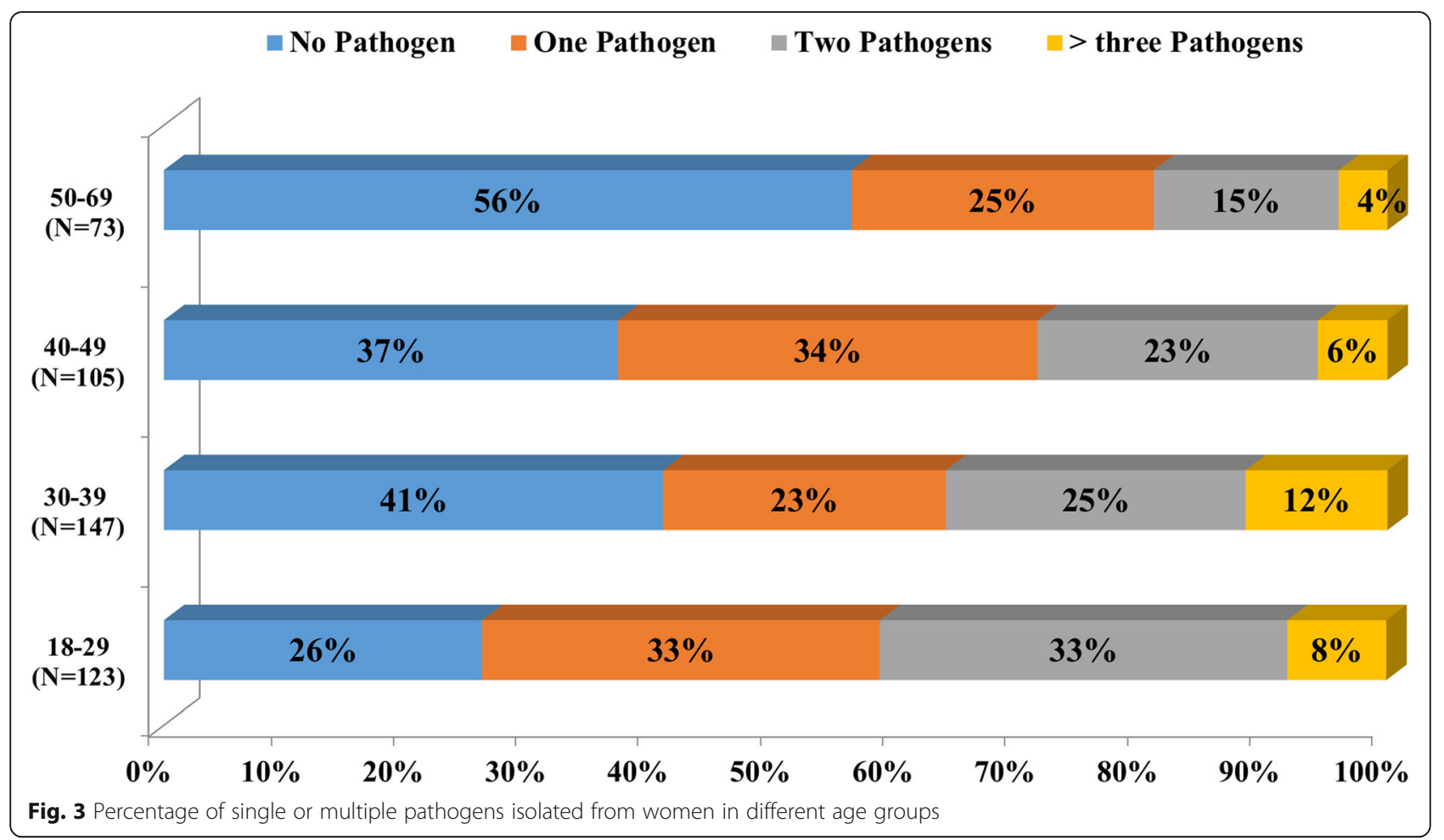

significantly associated with the type of contraceptive $(P=0.036)$, with a higher proportion among IUD users.

Table 3 presents univariate and multivariate logistic regression results for the presence of infection with the demographic and behavioral characteristics which appeared to be significant at the bivariate level. The univariate logistic regression odds ratio showed that being older or ever married were protective, while consuming alcohol or using an IUD were risk factors. In the multivariate analysis, after controlling for all characteristics significant at the bivariate level, only younger age and the use of IUD remain risk factors for infection. In fact, women appear to be 3 times more at risk of infection if they are between the ages of 18-29 compared to women older than 50. The use of an IUD more than doubles the risk of infection for women.

Table 3 Adjusted and unadjusted logistic regression results for the association between presence of infection and select demographic and behavioral risk factors $(n=373)$

\begin{tabular}{|c|c|c|c|c|c|c|}
\hline \multirow[t]{2}{*}{ Variable } & \multicolumn{3}{|c|}{ Unadjusted Results } & \multicolumn{3}{|c|}{ Adjusted Results ${ }^{1}$} \\
\hline & OR & $\mathrm{Cl}$ & $\mathrm{p}$ & OR & $\mathrm{Cl}$ & $p$ \\
\hline \multicolumn{7}{|l|}{ Age } \\
\hline $18-29$ & 3.644 & $1.973-6.727$ & 0.000 & 3.005 & $1.486-6.073$ & 0.002 \\
\hline $30-39$ & 1.858 & $1.053-3.277$ & 0.032 & 1.553 & $0.813-2.967$ & 0.182 \\
\hline $40-49$ & 2.168 & $1.180-3.985$ & 0.013 & 1.806 & $0.915-3.565$ & 0.089 \\
\hline $50-69$ & 1.000 & & & & & \\
\hline \multicolumn{7}{|l|}{ Marital status } \\
\hline Single & 1.000 & & & & & \\
\hline Married & 0.241 & $0.092-0.630$ & 0.004 & 0.364 & $0.087-1.526$ & 0.167 \\
\hline Divorced/widowed & 0.104 & $0.032-0.343$ & 0.000 & 0.211 & $0.041-1.081$ & 0.062 \\
\hline Alcohol consumption & 1.933 & $1.130-3.307$ & 0.016 & 1.309 & $0.632-2.709$ & 0.468 \\
\hline IUD use & 1.781 & $1.071-2.963$ & 0.026 & 2.024 & $1.158-3.537$ & 0.012 \\
\hline
\end{tabular}

Note: OR odds ratio; $95 \% \mathrm{Cl}$ 95\% confidence interval

1 model includes age, marital status, alcohol consumption and IUD use. 


\section{Discussion}

The aim of the present epidemiological study was to investigate the prevalence of STIs among women using a highly reliable, sensitive and cost effect diagnostic test for simultaneous detection of microorganisms. The results showed that STI pathogens are found in both symptomatic and asymptomatic women. Clinical management and treatment of these pathogens in asymptomatic individuals are challenging. On the other hand, the absence of pathogens in the presence of symptoms could be explained by the presence of microbiomes not yet identified or by disease of non-microbial origin.

\section{Low prevalence of $\mathrm{C}$. trachomatis and $\mathrm{N}$. gonorrhea}

This study presented a low prevalence of both C.trachomatis $(0.8 \%)$ and N.gonorrhoeae $(0.2 \%)$ including one asymptomatic coinfection. Our results were comparable to other studies in the Middle East and North Africa region (MENA) and the Eastern Mediterranean Region (EMR) which reported a prevalence ranging from 2.5 to $4.2 \%$ for C.trachomatis and 0.1 to $0.6 \%$ for N.gonorrhoeae [18-22]. The prevalence of both bacteria are reported to be higher in UK, France and American regions [19, 20, 23-27]. The low prevalence of these infections in Lebanon may relate to the fact that the majority of women were married and probably faithful to their husbands; few women reported to have multiple sexual partners.

\section{Prevalence of other genital pathogens}

Our study has found that among the mollicutes, U.parvum was the most frequently detected microorganism with an overall prevalence of $34.9 \%$, and the most isolated single pathogen. U.parvum was frequently associated with increased positivity for G.vaginalis, however, no significant association was found between the detection of both pathogens and symptoms. Neither U.parvum, U.urealyticum, nor G.vaginalis seem to be significantly associated with symptoms in females when isolated as a single pathogen; their role in the female urogenital tract therefore remains unknown, although reported cases have shown that these infections can cause cervicitis and bacterial vaginosis [28-30].

C.albicans, whose overall prevalence was lower than G.vaginalis, was not associated with symptoms and was mostly observed among women aged between 30 and 39 years (50\%). Candida species may persist for months, years and live in symbiosis with vaginal microbiota without causing any symptoms [31, 32]. However, acute vulvovaginal candidiasis can occur following colonization when there is breakdown in the symbiosis, which triggers the overgrowth of Candida or alteration in the protective defense mechanisms $[33,34]$.
New diagnostic assays such as nucleic acid testing improved the detection of T.vaginalis especially in asymptomatic individuals [35]. This may explain why the prevalence of T.vaginalis infection in our study was higher (2\%) than the one found in a previous study conducted in Lebanon (1.2\%) [36]. T. vaginalis was also reported to be low in other industrialized countries [21, 37].

\section{Genotypic distribution of HPV genotypes}

HPV genotypes were investigated to provide an insight into the need for HPV vaccination at sexual debut or early adolescence age. The prevalence of HPV in our study sample was $6.7 \%$ which is in concordance with the results of a meta-analysis that was conducted in 2012 on HPV in the MENA region [38]. The age distribution of HPV infection in the current study reflects the natural history of HPV infection. HPV rates peaked at the age of 20 to $29(47 \%)$ almost after the start of the women sexual activity [39]. However, the HPV infection in women of a young age is often temporary and is cleared by their immune system. The occurrence of HPV was reported in $10 \%$ of women aged between 50 and 69 . The latter could be explained by new acquisitions of the virus following a new sexual partner, changes in sexual practices, reactivation of the latent uncleared infection due to reduced immunity with aging or survival bias due to death of women who developed cervical cancer [40].

Data on the prevalence and genotype distribution of HPV infection in Lebanon are limited. The most frequently detected HPV genotypes among women were the HR-HPVs. Our study found that HPV16 (38\%), HPV 18 (21\%) HPV51 (18\%), HPV 26 (15\%), HPV39 (15\%), and HPV 73 (12\%) were the six predominant genotypes in the sample. If the immune system fails to clear the HR-HPV types, infections will be associated with high risk for cervical disease progression leading to cervical cancer [41].

WHO has issued a document on controlling cancer in the Eastern Mediterranean region where only 35\% of cervical cancer were reported at early stages while the rest were discovered at later stages; the latter are usually associated with bad prognosis and minimal recovery rate [42]. Another meta-analysis study, conducted at the international level, showed that at an unspecified point in time, $11.7 \%$ of women with normal cervical cytological findings were positive for HPV infection; of which $70 \%$ were carcinogenic HPV types. The main variables affecting such data were age and geography [39]. In our study, five women had normal cytology in the presence of HR-HPV. In Lebanon, most clinicians use cytology screening for cervical cancer once a year instead of HR HPV-based screening, which may affect the early detection and treatment of 
women. Adding to that, the national prevalence of "ever used" of the PAP smear is 35\% [43]. Cotesting PAP test and HR-HPV in women aged 30 years and older is more sensitive in detecting abnormal cells or cervical cancer than a Pap test alone; both are essential to decrease cervical cancer incidence in the Mediterranean region [44, 45]. Awareness campaigns on the advantages of early detection using contesting, particularly among vulnerable women, would reduce the incidence of cervical cancer.. Health care providers should insight women to regularly perform their screening test.

\section{Prevalence of HR-HPV genotypes and efficacy of HPV vaccine}

In any country, it is necessary to know the HPV genotype distribution to assess the effectiveness of vaccines recommended by the gynecologists. The predominance of HR-HPV in our study favors the recommendation of HPV vaccination. Currently available HPV vaccines are Gardasil, Gardasil 9, and Cervarix $[46,47]$; all 3 vaccines prevent infections with HPV types 16 and 18. Although Gardasil 9 protects against infection with additional HPV types such as 6, 11, 31, $33,45,52$ and 58; it excludes other types of infections prevalent in the region such as type $51,26,39$ and 73. According to the International Agency for Research on Cancer, HPV 51 and HPV 26 has been defined as human carcinogens [48]. Cross protection of Gardasil 9 against these various types should be further investigated.

HPV vaccines are still expensive in Lebanon, not yet recommended by all pediatricians and not offered by the Lebanese government as part of the national immunization program. The ministry of health in Lebanon should implement a systemic approach for HPV vaccination similar to that initiated by an international organization, GAVI, who helped 30 countries to introduce HPV vaccines into their national immunization programs with the aim to protect around 40 million girls from cervical cancer by $2020[49,50]$.

\section{Association between risk factors and infections}

In this study, STIs were common in single (86\%) and married women $(61 \%)$ indicating that sexual behavior could be associated with infection [51]. Women may possibly engage in risky sexual acts to achieve motherhood or to sexually satisfy their partner. More information about women's sexual behavior was hindered by the taboo around sexual disclosure. In the current study, the total number of single women who participated was low since the annual gynecologic exam as a routine checkup for single women is not a common practice in Lebanon.
The use of IUD in women was high reaching 54\%; $72 \%$ of those were positive for the infection. Previous studies showed an association between IUD and pelvic inflammatory diseases among women with sexually transmitted infection [52]. The risk may vary depending on when the IUD was inserted, whether prior to bacterial exposure or afterwards. The IUD can be safe and effective if inserted under aseptic conditions.

This study has also shown an association between STIs and alcohol consumptions (73\%). The latter could have an impact on the sexual behavior of women and their sexual arousal [51, 53-56].

\section{Strengths and limitations}

In Lebanon and the MENA region, this is the first study that presents data about the prevalence of STIs among women by simultaneous detection of 11 pathogens and describes the distribution of circulating HR-HPV and LR-HPV genotypes. It also identifies various risk factors associated with STIs.

However, the prevalence of other STIs such as HSV, Hemophilus ducreyi, Treponema pallidum and blood born viruses (HBV, HCV and HIV) were not investigated. The sample chosen is convenient and limited in its majority to married women, it also excluded non pregnant women. Future research directions should include STI screening for men and women of different age groups at the national level.

\section{Conclusion}

The results of this study should trigger the healthcare professionals to implement reproductive healthcare services that are accessible and affordable for all. Awareness campaigns are also necessary for the population to adopt a healthy sexual behavior.

\section{Supplementary information}

Supplementary information accompanies this paper at https://doi.org/10. 1186/s12879-020-05066-8.

Additional file 1: Table S1. Nucleotide sequences of primers and probes

Additional file 2: Table S2. HPV genotypes distribution patterns detected in 34 samples

Additional file 3: Table S3. Comparison of Pap smear results with HPV genotyping findings of $17 \mathrm{HPV}$ positive patients

\section{Abbreviations}

STIs: Sexually transmitted infections (STIs); CDC: Centers for Disease Control; WHO: World Health Organization; MENA: Middle East and North Africa; HPV: Human papilloma virus; CT: Chlamydia.trachomatis; NG: Neisseria.gonorrhoeae; MG: Mycoplasma.genitalium; MGI: Mycoplasma.girerdii; MH: Mycoplasma hominis; UU: Ureaplasma.urealyticum; UP: Ureaplasma parvum; GV: Gardnerella vaginalis; CA: Candida albicans; TV: Trichomonas vaginalis; PAP: Papanicolaou; HR-HPV: High risk-human papilloma virus; LR-HPV: Low risk- human papilloma virus; PCR: Polymerase Chain reaction; IUD: Intrauterine device; 
OR: Odds ratio; Cl: Confidence interval; HBV: Hepatitis B virus; HCV: Hepatitis C virus; HIV: Human immunodeficiency virus; GAVl: Global Alliance for Vaccines and Immunisation

\section{Acknowledgements}

We are very grateful to Dr. Ziad Baba, Mrs. Mirna Olleik, Mrs. Dalina Muawad, Mrs. Ghina Rawas for their contribution in the data collection.

\section{Availability of data and material}

All data generated or analysed during this study are included in this published article and its supplementary information files.

\section{Authors' contributions}

MEC supervised and analyzed the experiments and was responsible for writing up the manuscript. JH and RY performed and analyzed the experiments in addition to data analysis. MC helped in developing the methodology for microbial detection. MA, RB and JY helped in the epidemiological and statistical analysis of the data. RS, CA, TS, SI, MH, TEJ, FH were responsible for the study design, sampling and clinical interpretation. All authors reviewed the manuscript.

\section{Funding}

The project was funded by the Lebanese Council for Scientific Research and by the University of Balamand Internal Research Grant. The funders had no role in study design, data collection and analysis, decision to publish, or preparation of the manuscript.

\section{Ethics approval and consent to participate}

Study activities were reviewed by the institutional review board of Saint George Hospital (Number: 009, Date: 2016) and Makassed General Hospital (Name: Mira El Chaar, Date: 2016).

A written informed consent was obtained from all eligible women before entering the study. Women were informed about the study, their participation was voluntary and they had the right to withdraw at any moment. The risks and benefits were clearly explained.

\section{Consent for publication}

\author{
Not applicable.
}

\section{Competing interests}

All authors declare that they have no competing interests.

\section{Author details}

${ }^{1}$ Faculty of Health Sciences, University of Balamand, P.O.Box 166378 Ashrafieh, Beirut 1100-2807, Lebanon. ${ }^{2}$ Public Health England Clinical Microbiology Laboratory, Addenbrooke's Hospital, Cambridge, UK. ${ }^{3}$ Faculty of Medicine, University of Balamand, Beirut, Lebanon. ${ }^{4}$ Department of Obstetrics and Gynecology, Saint George Hospital University Medical Center, Beirut, Lebanon. ${ }^{5}$ Makassed General Hospital, Beirut, Lebanon. ${ }^{6}$ National Institution of Social Care and Vocational Training, Beirut, Lebanon.

Received: 19 December 2019 Accepted: 3 May 2020 Published online: 27 May 2020

\section{References}

1. Sexually transmitted infections [https://www.who.int/news-room/factsheets/detail/sexually-transmitted-infections-(stis)].

2. Adachi K, Nielsen-Saines K, Klausner JD. Chlamydia trachomatis Infection in Pregnancy: The Global Challenge of Preventing Adverse Pregnancy and Infant Outcomes in Sub-Saharan Africa and Asia 2016; 2016. p. 9315757.

3. Malhotra M, Sood S, Mukherjee A, Muralidhar S, Bala M. Genital chlamydia trachomatis: an update. Biomed Res Int. 2013;138(3):303-16.

4. Moodley P, Sturm AW. Sexually transmitted infections, adverse pregnancy outcome and neonatal infection. Seminars Neonatology. 2000;5(3):255-69.

5. Paavonen J, Eggert-Kruse W. Chlamydia trachomatis: impact on human reproduction. Hum Reprod Update. 1999:5(5):433-47.

6. Tsevat DG, Wiesenfeld HC, Parks C, Peipert JF. Sexually transmitted diseases and infertility. Am J Obstet Gynecol. 2017;216(1):1-9.

7. Robinet $S$, Parisot F. Accreditation of a multiplex real time PCR assay for detection and semi-quantitative determination of pathogens responsible of sexually-transmitted infections. Ann Biol Clin. 2018;76(4):459-76.
8. Del Prete R, Ronga L, Lestingi M, Addati G, Angelotti UF, Di Carlo D, Miragliotta G. Simultaneous detection and identification of STI pathogens by multiplex real-time PCR in genital tract specimens in a selected area of Apulia, a region of southern Italy. Infection. 2017;45(4):469-77.

9. Global Healh strategy on sexually transmitted infections 2016-2021 toward ending STI's [https://apps.who.int/iris/bitstream/handle/10665/246296/WHORHR-16.09-eng.pdf;sequence=1].

10. El-Kak F. Sexuality and sexual health: constructs and expressions in the extended Middle East and North Africa. Vaccine. 2013;31(Suppl 6):G45-50.

11. Ghandour LA, Mouhanna F, Yasmine R, El Kak F: Factors associated with alcohol and/or drug use at sexual debut among sexually active university students: cross-sectional findings from Lebanon. BMC Public Health 2014, 14:671.

12. Wagner GJ, Aunon FM, Kaplan RL, Karam R, Khouri D, Tohme J, Mokhbat J. Sexual stigma, psychological well-being and social engagement among men who have sex with men in Beirut, Lebanon. Culture Health Sexuality. 2013;15(5):570-82.

13. Sample Size Calculator by Raosoft, Inc. [www.raosoft.com/samplesize.html].

14. Jalal H, Stephen H, Alexander S, Carne C, Sonnex C. Development of realtime PCR assays for genotyping of chlamydia trachomatis. J Clin Microbiol. 2007:45(8):2649-53.

15. Qu W, Jiang G, Cruz Y, Chang CJ, Ho GY, Klein RS, Burk RD. PCR detection of human papillomavirus: comparison between MY09/MY11 and GP5+/GP6+ primer systems. J Clin Microbiol. 1997;35(6):1304-10.

16. Latsuzbaia A, Tapp J, Nguyen T, Fischer M, Arbyn M, Weyers S, Mossong J. Analytical performance evaluation of Anyplex II HPV28 and Euroarray HPV for genotyping of cervical samples. Diagn Microbiol Infect Dis. 2016;85(3):318-22.

17. Cornall AM, Poljak M, Garland SM, Phillips S, Machalek DA, Tan JH, Quinn MA, Tabrizi SN. EUROarray human papillomavirus (HPV) assay is highly concordant with other commercial assays for detection of high-risk HPV genotypes in women with high grade cervical abnormalities. Eur J Clin Microbiol Infect Dis. 2016:35(6):1033-6.

18. Al-Thani A, Abdul-Rahim H, Alabsi E, Bsaisu HN, Haddad P, Mumtaz GR, AbuRaddad $L$. Prevalence of Chlamydia trachomatis infection in the general population of women in Qatar. Sexually Transmitted Infect. 2013;89(Suppl 3):iii57-60.

19. Ramia S, Kobeissi L, El Kak F, Shamra S, Kreidieh K, Zurayk H. Reproductive tract infections (RTIS) among married non-pregnant women living in a lowincome suburb of Beirut, Lebanon. J Infect Dev Countries. 2012;6(9):680-3.

20. Mahafzah AM, Al-Ramahi MQ, Asa'd AM, El-Khateeb MS. Prevalence of sexually transmitted infections among sexually active Jordanian females. Sex Transm Dis. 2008;35(6):607-10.

21. Rowley J, Vander Hoorn S, Korenromp E, Low N, Unemo M, Abu-Raddad LJ, Chico RM, Smolak A, Newman L, Gottlieb S, et al. Chlamydia, gonorrhoea, trichomoniasis and syphilis: global prevalence and incidence estimates, 2016. Bull World Health Organ. 2019;97(8):548-562p.

22. Smolak A, Chemaitelly H, Hermez JG, Low N, Abu-Raddad L. Epidemiology of chlamydia trachomatis in the Middle East and North Africa: a systematic review, meta-analysis, and meta-regression. Lancet Glob Health. 2019;7(9): e1197-225.

23. Sonnenberg P, Clifton S, Beddows S, Field N, Soldan K, Tanton C, Mercer CH, da Silva FC, Alexander S, Copas AJ, et al. Prevalence, risk factors, and uptake of interventions for sexually transmitted infections in Britain: findings from the National Surveys of sexual attitudes and lifestyles (Natsal). Lancet. 2013; 382(9907):1795-806

24. Torrone E, Papp J, Weinstock H. Centers for disease C, prevention: prevalence of chlamydia trachomatis genital infection among persons aged 14-39 years--United States, 2007-2012. MMWR Morb Mortal Wkly Rep. 2014; 63(38):834-8.

25. Goulet V, de Barbeyrac B, Raherison S, Prudhomme M, Semaille C, Warszawski J, group CSF. Prevalence of chlamydia trachomatis: results from the first national population-based survey in France. Sex Transm Infect. 2010;86(4):263-70

26. Luo ZZ, Li W, Wu QH, Zhang L, Tian LS, Liu LL, Ding Y, Yuan J, Chen ZW, Lan LN, et al. Population-based study of chlamydial and gonococcal infections among women in Shenzhen, China: implications for programme planning. PLoS One. 2018;13(5):e0196516.

27. Chan PA, Robinette A, Montgomery M, Almonte A, Cu-Uvin S, Lonks JR, Chapin KC, Kojic EM, Hardy EJ. Extragenital infections caused by chlamydia trachomatis and Neisseria gonorrhoeae: a review of the literature. Infect Dis Obstet Gynecol. 2016;2016:5758387. 
28. Liu L, Cao G, Zhao Z, Zhao F, Huang Y. High bacterial loads of Ureaplasma may be associated with non-specific cervicitis. Scand J Infect Dis. 2014;46(9): 637-41.

29. Rodrigues MM, Fernandes PA, Haddad JP, Paiva MC, Souza Mdo C, Andrade TC, Fernandes AP. Frequency of chlamydia trachomatis, Neisseria gonorrhoeae, mycoplasma genitalium, mycoplasma hominis and Ureaplasma species in cervical samples. J Obstetrics Gynaecology. 2011;31(3):237-41.

30. Paavonen J, Critchlow CW, DeRouen T, Stevens CE, Kiviat N, Brunham RC, Stamm WE, Kuo CC, Hyde KE, Corey L, et al. Etiology of cervical inflammation. Am J Obstet Gynecol. 1986;154(3):556-64.

31. Hall RA, Noverr MC. Fungal interactions with the human host: exploring the spectrum of symbiosis. Curr Opin Microbiol. 2017;40:58-64.

32. Prieto D, Correia I, Pla J, Roman E. Adaptation of Candida albicans to commensalism in the gut. Future Microbiol. 2016;11(4):567-83.

33. Sobel JD. Vulvovaginal candidosis. Lancet (London, England). 2007; 369(9577):1961-71.

34. Sobel JD. Recurrent vulvovaginal candidiasis. Am J Obstet Gynecol. 2016; 214(1):15-21.

35. Muzny CA, Blackburn RJ, Sinsky RJ, Austin EL, Schwebke JR. Added benefit of nucleic acid amplification testing for the diagnosis of Trichomonas vaginalis among men and women attending a sexually transmitted diseases clinic. Clin Infect Dis. 2014;59(6):834-41.

36. Deeb ME, Awwad J, Yeretzian JS, Kaspar HG. Prevalence of reproductive tract infections, genital prolapse, and obesity in a rural community in Lebanon. Bull World Health Organ. 2003:81(9):639-45.

37. Bouchemal K, Bories C, Loiseau PM. Strategies for prevention and treatment of Trichomonas vaginalis infections. Clin Microbiol Rev. 2017;30(3):811-25.

38. Seoud M. Burden of human papillomavirus-related cervical disease in the extended middle east and North Africa-a comprehensive literature review. J Lower Genital Tract Dis. 2012;16(2):106-20.

39. Bruni L, Diaz M, Castellsague X, Ferrer E, Bosch FX, de Sanjose S. Cervical human papillomavirus prevalence in 5 continents: meta-analysis of 1 million women with normal cytological findings. J Infect Dis. 2010;202(12):1789-99.

40. Smith JS, Melendy A, Rana RK, Pimenta JM. Age-specific prevalence of infection with human papillomavirus in females: a global review. JAdolescent Health. 2008:43(4 Suppl):S5-25 S25.e21-41.

41. de Martel C, Ferlay J, Franceschi S, Vignat J, Bray F, Forman D, Plummer M. Global burden of cancers attributable to infections in 2008: a review and synthetic analysis. Lancet Onco. 2012;13(6):607-15.

42. Organization $\mathrm{WH}$ : Towards a strategy for cancer control in the eastern Mediterranean region. 2009.

43. Bou-Orm IR, Sakr RE, Adib SM. Cervical cancer screening among Lebanese women. Revue d'epidemiologie et de sante publique. 2018;66(1):1-6.

44. Tracht JM, Davis AD, Fasciano DN, Eltoum IA. Discrepant HPV/cytology cotesting results: are there differences between cytology-negative versus HPV-negative cervical intraepithelial neoplasia? Cancer Cytopathology. 2017; 125(10):795-805.

45. Tracht J, Wrenn A, Eltoum IE. Primary HPV testing verification: a retrospective ad-hoc analysis of screening algorithms on women doubly tested for cytology and HPV. Diagn Cytopathol. 2017;45(7):580-6.

46. Maver PJ, Poljak M. Progress in prophylactic human papillomavirus (HPV) vaccination in 2016: a literature review. Vaccine. 2018;36(36):5416-23.

47. Harper DM, DeMars LR. HPV vaccines - a review of the first decade. Gynecol Oncol. 2017;146(1):196-204.

48. Schiffman M, Castle PE, Jeronimo J, Rodriguez AC, Wacholder S. Human papillomavirus and cervical cancer. Lancet (London, England). 2007; 370(9590):890-907

49. Kane MA, Serrano B, de Sanjose S, Wittet S. Implementation of human papillomavirus immunization in the developing world. Vaccine. 2012; 30(Suppl 5):F192-200.

50. Human papillomavirus vaccine support. Gavi, the Vaccine Alliance website. Available from: http://www.gavi.org/support/nvs/human-papillomavirus/.

51. Jonsson M, Karlsson R, Rylander E, Gustavsson A, Wadell G. The associations between risk behaviour and reported history of sexually transmitted diseases, among young women: a population-based study. Int J STD AIDS. 1997;8(8):501-5

52. Mohllajee AP, Curtis KM, Peterson HB. Does insertion and use of an intrauterine device increase the risk of pelvic inflammatory disease among women with sexually transmitted infection? A systematic review. Contraception. 2006;73(2):145-53.
53. George WH, Stoner SA. Understanding acute alcohol effects on sexual behavior. Ann Rev Sex Res. 2000;11:92-124.

54. Hutton HE, McCaul ME, Santora PB, Erbelding EJ. The relationship between recent alcohol use and sexual behaviors: gender differences among sexually transmitted disease clinic patients. Alcohol Clin Exp Res. 2008;32(11):2008-15.

55. Li M, McDermott R. Smoking, poor nutrition, and sexually transmitted infections associated with pelvic inflammatory disease in remote North Queensland indigenous communities, 1998-2005. BMC Womens Health. 2015;15:31.

56. Berg CJ, Painter JE, Sales JM, Mays D, Rose E, Wingood GM, Diclemente RJ. Smoking as a risk factor for STI diagnosis among African American females. Am J Health Behav. 2012;36(4):505-12.

\section{Publisher's Note}

Springer Nature remains neutral with regard to jurisdictional claims in published maps and institutional affiliations.
Ready to submit your research? Choose BMC and benefit from:

- fast, convenient online submission

- thorough peer review by experienced researchers in your field

- rapid publication on acceptance

- support for research data, including large and complex data types

- gold Open Access which fosters wider collaboration and increased citations

- maximum visibility for your research: over $100 \mathrm{M}$ website views per year

At BMC, research is always in progress.

Learn more biomedcentral.com/submissions 